\title{
Bacterial Distribution in Teeth with Pulp Necrosis and Apical Granuloma
}

Francisco Carlos Ribeiro, Alberto Consolaro, Tiago Novaes Pinheiro

\begin{abstract}
Aim: To evaluate the distribution of bacteria in teeth with pulp necrosis and apical granuloma.

Materials and methods: Thirty-two extracted teeth with pulp necrosis and apical granulomas and 16 cases of isolated apical granulomas were sectioned and stained with Hematoxylin and Eosin (H\&E) and Brown-Brenn staining for microscopic evaluation. The specimens were observed as to the location and distribution of bacteria involved in the process of pulp necrosis and their relationship with the periapical tooth structures and soft tissues.
\end{abstract}

Results: Stainable Gram-positive and Gram-negative bacteria were found in the entire root canal system. Bacterial biofilms were detected in $81.2 \%$ of cementum root canal, $46.8 \%$ in apical delta, $65.6 \%$ at the apical surface and $79.2 \%$ of the granulomas above all the specimens. Bacteria and bacterial biofilms were present in the entire root canal system of the infected teeth with apical granulomas.

Conclusion: Our findings suggest that bacterial infections can reach inaccessible areas to instrumentation.

Keywords: Biofilms, Bacterial infection, Root canal, Pulp necrosis, Apical granuloma.

How to cite this article: Ribeiro FC, Consolaro A, Pinheiro TN. Bacterial Distribution in Teeth with Pulp Necrosis and Apical Granuloma. Int J Experiment Dent Sci 2013;2(2):86-91.

Source of support: Nil

Conflict of interest: None declared

\section{INTRODUCTION}

Microbial biofilms are a very organized microbial structure above a determined surface composed of a variety of different microbial species sharing the same environment in a synergic, antagonist or symbiotic way. The formation of biofilms can occur on inert surfaces such as plastic or metallic and even biologic surfaces like dental, mucosal and bonny surfaces. As the biofilms thicken and mature, certain adherent cells proliferate and elaborate exopolysaccharides until they produce a microcolony in which morphologically similar 'sister' cells are embedded in a thick polysaccharide matrix. This intercellular 'gel' protects the microbial body against antibodies, complement proteins, leukocytes and medications. Therefore, the microbial biofilms promotes protection and subsequent physical-chemical resistance to bacteria that is related to its structure. ${ }^{1}$

Considering all sorts of living forms that can be part of biofilm structure, such as fungus, virus and parasites, ${ }^{2}$ the most precise nomenclature form should be "microbial biofilm;' however, 'bacterial biofilms' is a very current form also applied.

Bacteria play an important role in the etiopathogenesis of pulp and periapical pathologies. ${ }^{3}$ Infected root canal treatment consisting of cleaning and shaping reduces great number of bacteria; however, it does not completely eliminate them. This bacterial contamination brings about inflammatory processes, either resorptive or of cellular biopathology, ultimately leading to necrosis in case therapeutic measures are not adopted. ${ }^{4}$

Bacterial seal of the root canal by filling is considered critical to prevent reinfection of the canal system. Even under the most ideal conditions, such extracted teeth, root fillings may not be performed such that leakage of dyes, bacterial elements and cells are prevented. ${ }^{5-7}$ A substantial number of studies support one-visit endodontic therapy. ${ }^{8,9}$ It is clinically well known that recurrent or refractory cases exist. ${ }^{10}$ The means of dissemination of these microorganisms in the root canal system and their biological characteristics are important for the establishment of endodontic therapy and are directly related to the chance of a successful treatment. $^{11-13}$

In this study, we investigated the distribution and relationship of bacteria and bacterial colonies inside the root canal system, in the structures of the mineralized root tissues and periapical granulomas, either in isolation or combined with the affected tooth. Moreover, an attempt was made to identify the types of microorganisms related to these pathological processes by means of Brown-Brenn staining, ${ }^{14}$ which highlights Gram-positive and Gram-negative bacteria, besides verification of the means through which they are related to the tooth structures and in the periapical granuloma.

\section{MATERIALS AND METHODS}

\section{Criteria for Sample Selection}

A total of 32 dental roots were selected, fulfilling the criteria which displayed periapical lesions firmly adhered to their apexes and had been previously microscopically diagnosed as periapical granulomas; the sample also comprised 16 cases with sections of periapical granulomas, previously submitted to microscopic evaluation as well. The dental roots, as well as the periapical granulomas were selected from the routine archives of the Pathology Laboratory at Bauru Dental School. Consent for use of tissue from humans was obtained by a research ethics committee. 


\section{Tissue Processing}

The specimens presenting with mineralized structures were submitted to demineralization with 5\% EDTA solution ( $\mathrm{pH}$ 7.0). After embedding in paraffin, the specimens were divided into three groups: (A) comprising 16 teeth with longitudinally sectioned periapical granulomas, (B) composed of 16 teeth with transversely sectioned periapical granulomas; and (C) including 16 periapical granulomas.

The specimens were semiserially sectioned at $5 \mu \mathrm{m}$, with nine additional sections immediately after detection of a section displaying the root canal lumen continuous with the periapical lesion. After sectioning and mounting on slides, two staining methods were employed: Hematoxylin and Eosin (H\&E), for general analysis of the structures; and Brown-Brenn, for highlighting of bacteria and bacterial colonies.

\section{Analytic Procedure}

Analysis of the results was followed by observation of the microscopic morphologic findings, which were recorded in tables and photomicrographed. Phenomena and morphological aspects that could be recorded were grouped according to the location, with special emphasis to the dentin root canal, the dentin in the cementum root canal, the apical surface and the periapical granulomas. Also the distribution of bacteria and bacterial colonies involved in the process of pulp necrosis, as well as their relationship with the periapical tooth structures and soft tissues and the induction of apical granuloma in the teeth affected was analyzed.

\section{RESULTS}

Distribution of the microscopic findings of the study is displayed in Tables 1 and 2. The microscopic aspects of the apical third, its relationship with the periapical granuloma and the close association with the root canal system are demonstrated in Figures 1A to D, which highlights the presence of bacterial colonies inside the root canal lumen, adhered to Howship's lacunae at the apical surface, and also inside the apical granuloma. Morphological analysis of the inner root surface at the apical third in most specimens highlights irregularities, with areas of reparative dentin, on which bacterial niches are frequently found on the structural defects.

Pulp nodules of different sizes were observed close to the root canal walls or adhered to them in three specimens.

Table 1: Bacterial distribution according to the study groups, as to their location in the tooth structures and apical granulomas

\begin{tabular}{|c|c|c|c|c|c|c|}
\hline \multirow[t]{2}{*}{ Bacteria } & \multirow[t]{2}{*}{ Location } & \multicolumn{3}{|c|}{ Groups } & \multirow[t]{2}{*}{ Total } & \multirow[t]{2}{*}{ Percentage (\%) } \\
\hline & & Group A & Group B & Group C & & \\
\hline \multirow[t]{3}{*}{ Root canal } & Dentin root canal & 16 & 16 & - & 32 & 100 \\
\hline & Cementum root canal & 11 & 15 & - & 26 & 81.2 \\
\hline & Apical delta & 7 & 8 & - & 15 & 46.8 \\
\hline \multirow[t]{3}{*}{ Dentin } & Pulp third & 6 & 9 & - & 15 & 46.8 \\
\hline & Middle third & 7 & 3 & - & 10 & 31.2 \\
\hline & Surface third & 2 & 3 & - & 5 & 15.6 \\
\hline \multirow[t]{5}{*}{ Cementum root canal } & Lumen & 8 & 15 & - & 23 & 71.9 \\
\hline & Howship's lacunae & 10 & 8 & - & 18 & 56.2 \\
\hline & Cementum & 10 & 8 & - & 18 & 56.2 \\
\hline & Dentin & 4 & 6 & - & 10 & 31.2 \\
\hline & Cementoplasty & 7 & 8 & - & 15 & 46.8 \\
\hline \multirow[t]{2}{*}{ Apical surface } & Present & 10 & 11 & - & 21 & 65.6 \\
\hline & Absent & 6 & 5 & - & 11 & 34.4 \\
\hline \multirow[t]{5}{*}{ Granulomas } & Extracellular & 10 & 15 & 13 & 38 & 79.2 \\
\hline & Intracellular & 10 & 15 & 13 & 38 & 79.2 \\
\hline & Central & 3 & 5 & 0 & 8 & 16.7 \\
\hline & Peripheral & 1 & 3 & 3 & 7 & 14.6 \\
\hline & Related to the apex & 10 & 8 & 0 & 18 & 37.5 \\
\hline
\end{tabular}

Table 2: Characterization of the bacteria as to their morphology and characterization, according to the Gram's method, in the different structures analyzed

\begin{tabular}{|c|c|c|c|c|c|}
\hline \multirow[t]{2}{*}{ Bacteria specimens } & \multicolumn{3}{|c|}{ Morphology resemblance } & \multicolumn{2}{|c|}{ Types } \\
\hline & Cocci & Bacilli & $\begin{array}{l}\text { Spirillum } \\
\text { Vibrio }\end{array}$ & Gram + & Gram - \\
\hline Root canal & 31 & 32 & 11 & 32 & 31 \\
\hline Dentin & 29 & 29 & 0 & 29 & 29 \\
\hline Cementum root canal & 25 & 25 & 5 & 25 & 24 \\
\hline Surface & 20 & 19 & 2 & 20 & 19 \\
\hline Granulomas & 38 & 26 & 2 & 38 & 27 \\
\hline
\end{tabular}




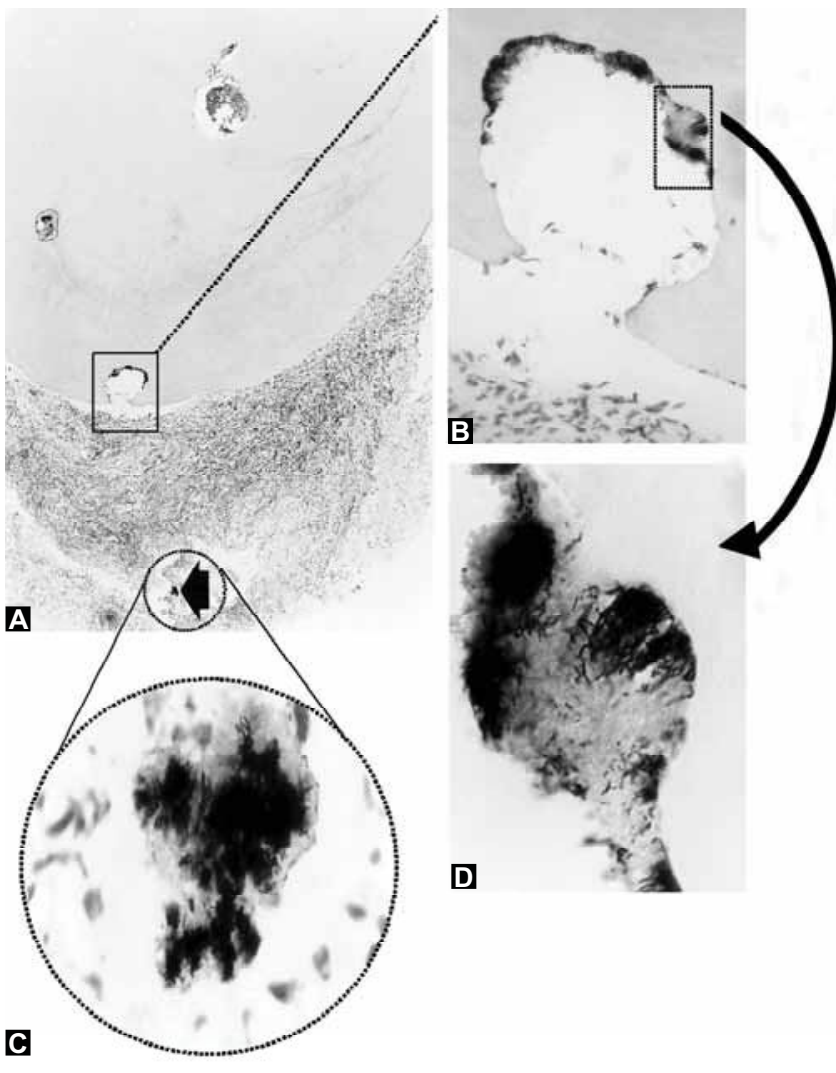

Figs 1A to D: Microscopic examination of the apical third of tooth with pulp necrosis and apical granuloma $(A)$. In (B and $C$ ) one can notice bacterial biofilms present inside Howship's lacunae at the apical surface and also inside the apical granuloma (D) in a transversal tissue section (Original magnification: A: 10x, B: 40x, C: $100 \times$ and D: $400 \times$, Brown-Brenn stain)

Reparative dentin and areas of dentin and/or cementum resorption were also found as major factors yielding morphological irregularities at the apical surfaces and in the root canal system. Some specimens displayed lacunae in dentin, either empty or filled by necrotic remnants and/ or bacterial colonies.

The apical root dentin was disorganized in most specimens, with obliteration of the dentinal tubules by reparative dentin or cementum. The reparative dentin induced by bacterial infection exhibits few and irregularly distributed dentinal tubules, with cellular inclusions in some cases. The low bacterial density inside the tubules contributed to preservation of the tubules, with predominance of Gramnegative species. Five specimens in 'A' had their dentinal tubules obstructed by reparative dentin or cementum projections at the most apical portion of the root.

The cementum root canal was characterized by the presence of resorption of varying degree, yielding significant anatomic alterations and acting as a niche for bacterial adhesion in the area. On the other hand, the tubules in the underlying dentin layer were free of bacteria. Two specimens demonstrated the formation of biofilms plugging the apical foramen (Figs. 2A to E). Another finding was the

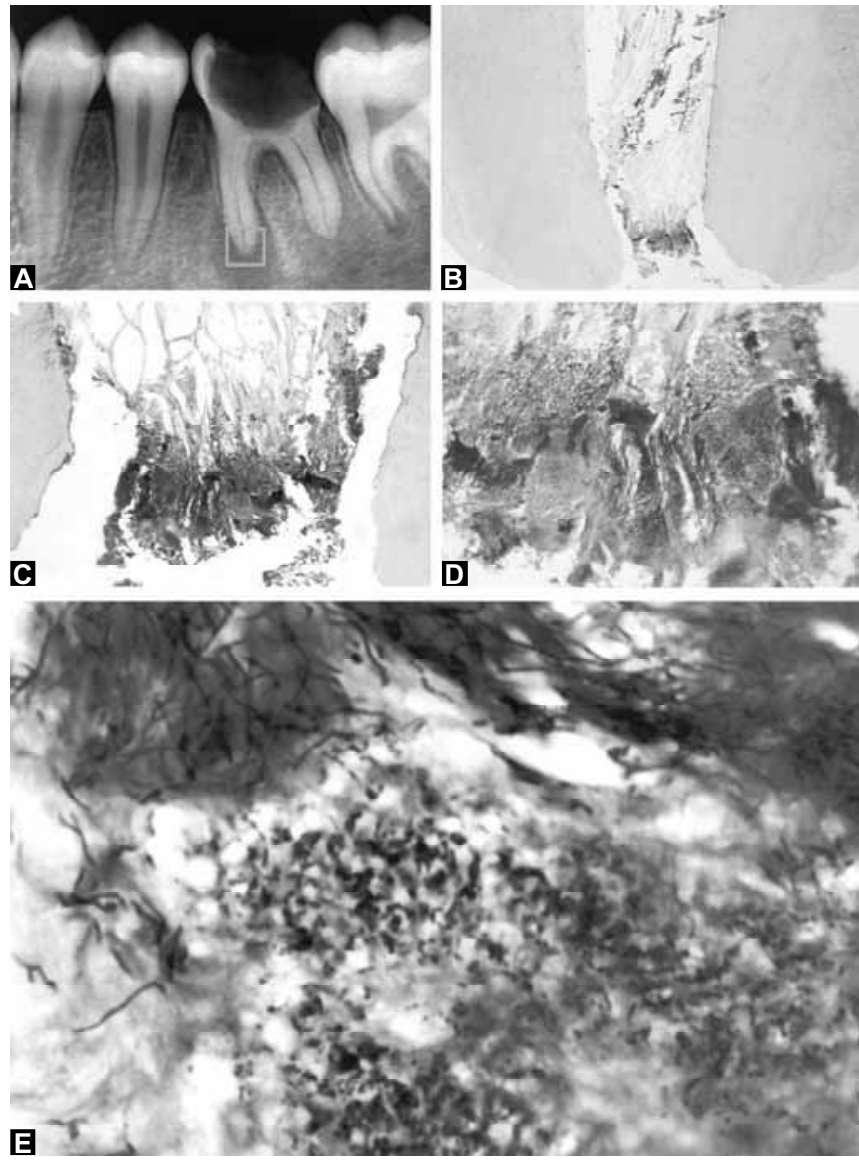

Figs $2 A$ to $E$ : In $(A)$, the radiograph that came along with one of the lesions included in this study: a mandible molar with a wide coronal destruction caused by dental caries before the extraction. Microscopically, the case was examined and diagnosed as apical granuloma. The tissue section demonstrates the foraminal area displaying a bacterial biofilm plugging the apical foramen (B to $D)$. Magnification of the area showed Gram-positive and Gram-negative bacteria (E). Original magnification: B: 10x, C: 100x, D: 160x and E: 1,000x, Brown-Brenn stain

accumulation of neutrophils, attracted by the large amount of bacteria at the beginning of the root canal system.

Figures $3 \mathrm{~A}$ to $\mathrm{D}$ displays bacterial colonies associated to the root canal wall, as well as bacterial invasion into dentinal tubules.

The apical surface exhibited irregularities secondary to the cementum resorptions, which extended up to the underlying dentin in some instances and might or not be filled by predominantly Gram-negative bacterial colonies comprising an association of bacilli, spirillum and cocci, with observation of bacterial biofilm adhered to the apical surface of 17 teeth (Figs 4A to F). The apical dentobacterial plaque, or apical biofilm, was characterized by the presence of bacterial colonies inside the root canal and bacteria located in intracellular vacuoles of macrophages.

The 16 specimens in group A displayed bacterial colonies containing Gram-positive and Gram-negative cocci and bacilli, necrotic remnants, besides vegetal cells found in seven specimens, probably of dietary origin. 


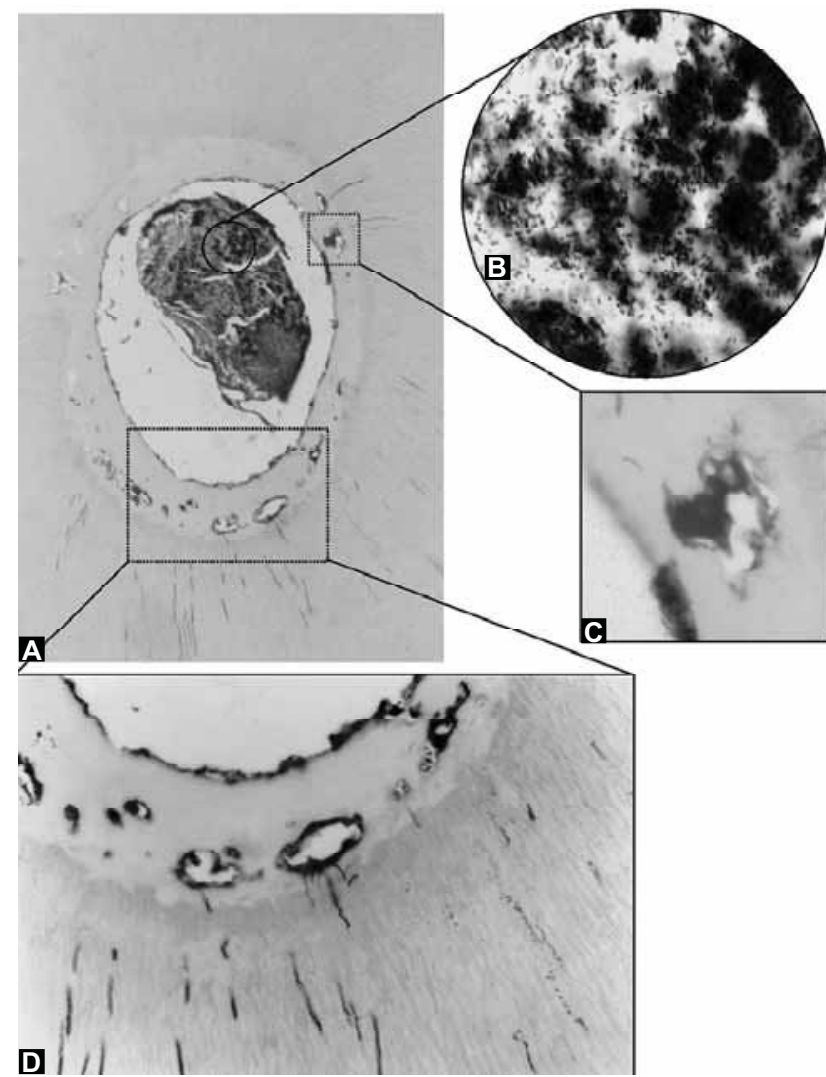

Figs 3A to D: Transversal dental section shows bacterial arrangement inside the root canal in (A). Note in (B) that the magnification of the area shows a great number of bacterial colonies well-organized ( $C$ and $D$ ) the presence of bacterial profiles inside the dentinal tubules and in the root canal wall. Original magnification: A: 40x, B: 400x, C and D: 160x, BrownBrenn stain

The periapical granulomas adhered to these roots displayed a concentration of neutrophils close to the apical foramen and frequently exhibited isolated bacteria or bacterial colonies in the granulomatous tissue. Moreover, a close relationship was found between the lumen of the main canal, the accessory root canals constituting the apical dental, and the inter-relationship between the lateral root surface and the periapical granuloma in the 16 specimens in group $\mathrm{B}$. The openings corresponding to the foramens of the apical delta were clearly visible in eight specimens.

The periapical granulomas adhered to these roots were either laterally located or circumscribed the root apexes. Moreover, in group A, Gram-positive and Gram-negative bacteria were observed, in isolation and/or in colonies inside the periapical granulomas. Group $\mathrm{C}$, comprising the slides of periapical granulomas, aided in the observation of the organization of the inflammatory infiltrate and tissue components. The most relevant findings were the concentration of hyaline bodies of Russell, pseudoxanthomatous cells and epithelial rests of Malassez, randomly distributed inside the lesion. As to the presence of bacteria, there was
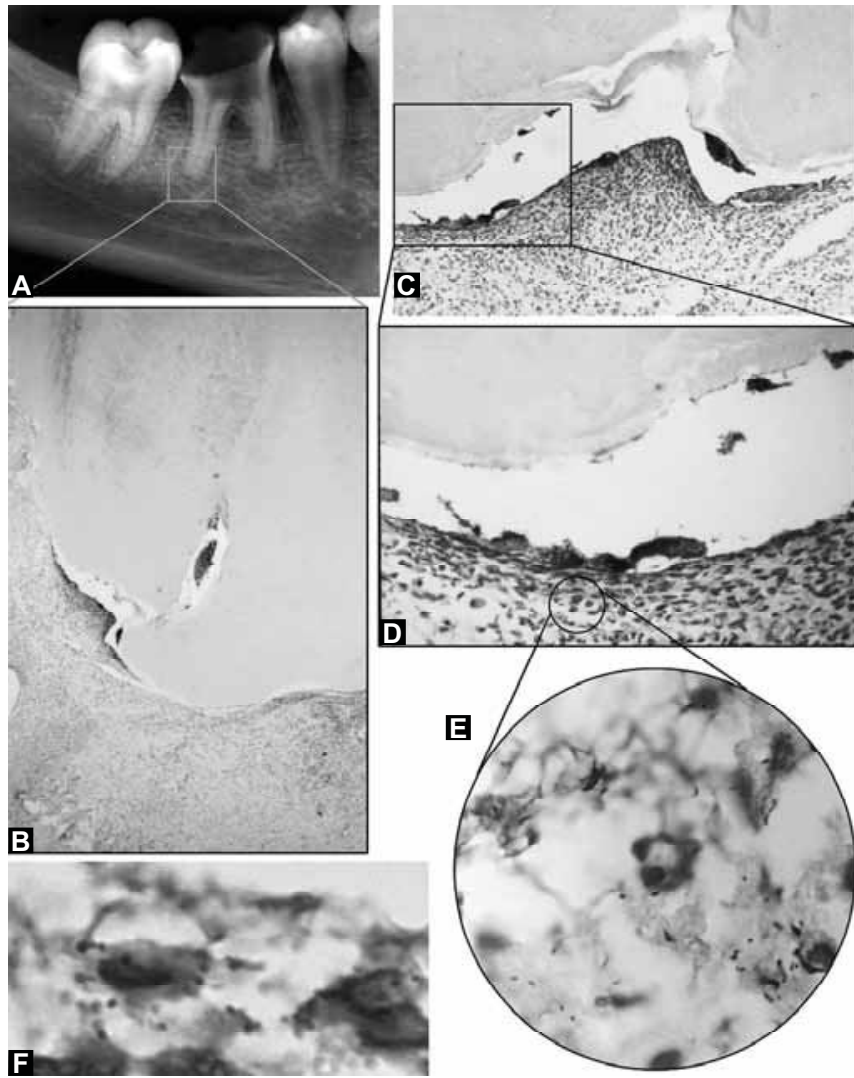

Figs 4A to F: Radiographic aspects of one of the cases studied (A): a mandible molar with a wide coronal destruction caused by dental caries before the extraction. Examination of apical tissues showed bacterial biofilms adhered to the apical root surface, constituted sessile or free-living bacteria (B and $C)$. $E$ and $F$ : the magnification demonstrates bacteria interacting with inflammatory cells inside the lesion. Original magnification: B: 10x, C: 100x, D: 160x, E and F: 1,000x, Brown-Brenn stain

predominance of Gram-positive bacteria in isolation inside the granulomas, either in the intercellular spaces or inside macrophage cells.

\section{DISCUSSION}

The presence of a successful root canal obturation demonstrated to play an important role in the absence of bacteria at the apical third of teeth, even when satisfactory fillings are lacking or crown fractures or even caries are observed, as reported by Ricucci and Bergenholtz. ${ }^{15}$ Our findings also led to a low incidence of bacteria inside the tubules at the apical third of teeth, which may be one of the factors influencing the high success rates of endodontic treatments. This observation reinforces the importance of a good sealing, so that bacteria occasionally remaining inside the dentinal tubules will have no substrate available for their survival.

On the other hand, if proper root canal sealing is missing or precarious, bacteria may be observed in all apical areas and related apical lesions, as in the present study. The irregularly distributed dentinal tubules found in some cases may either impair bacterial penetration in the dentinal 
tubules or facilitate the housing of bacterial colonies in the structural defects, whenever present.

Due to the large amount of bacteria present in the mineralized structures of the roots investigated, especially inside the main canal, even plugging the apical foramen as biofilms, this content should be carefully removed. The importance of root canal instrumentation associated to irrigants with bactericidal property and low surface tension in teeth with pulp necrosis must be emphasized. A step regarded as useful in such situations is the utilization of the crown-down pressureless technique, since it yields less extrusion of necrotic and bacterial remnants.

The findings of this study are compatible to those of Nair, ${ }^{2}$ who found Gram-positive bacilli inside accessory root canals. The presence of bacteria inside the dentinal tubules should also be taken into account, since Gram-positive and Gram-negative bacteria were found inside the tubules, being the Gram-negative cocci and bacilli the bacterial morphotypes resemblance most frequently observed. This bacterial content acts as a source of infection during or after endodontic treatment.

The bacterial density inside the radicular tubules was moderate, compared with the coronal dentin, on which tubular alterations characterized by 'varicosities' are common in the carious dentin, corroborating the studies of Akapta and Blechman. ${ }^{16}$ The possibility of infection after obturation should be emphasized, especially by bacteria close to the cementum enamel junction. ${ }^{17}$ These microorganisms may even remain undetected upon bacterial culture of the root canal contents before obturation ${ }^{11}$ thus, the bacteria may return to the root canal lumen from the depth of the dentinal tubules if there are gaps in the obturation.

The present study found a larger presence of bacteria in the cervical and middle thirds when compared to the apical third based on the low bacterial density observed in the internal root surface, and inside the dentinal tubules. Love ${ }^{13}$ had similar findings and suggested a clinical approach with minimum apical preparation with wider coronal instrumentation. The clinical practice based on this fact shall promote the reduction or elimination of bacteria from the pulp cavity and removal of the substrates they need. ${ }^{18}$

Bacteria and bacterial biofilms were also found in $81.2 \%$ of the cementum root canals and in the apical delta $46.8 \%$. These findings indicate that insufficient cleaning of the apical third might be the reason for many clinical failures due to the great anatomical complexity of the root canal system. Considering these findings, it is very advisable to agree with Nair ${ }^{19}$ that microbial agents can stay located in the uninstrumented recesses of the main canals, the isthmus communicating between them, and in accessory canals.
Inflammatory resorptions associated to the chronic periapical pathologies were found in most specimens, in agreement with previous authors. ${ }^{12,20,21}$ Verification of the presence of Gram-positive cocci and bacilli in lacunae left by the disorganized deposition of reparative dentin and in areas of resorption of cementum and root dentin corroborates the findings of Lin et al. ${ }^{12}$ Siqueira and Rôças, ${ }^{20}$ demonstrated the presence of infected debris inside the root canal and in the vicinity of the apical foramen.

Light microscopy revealed bacteria close to the apical surface of 21 specimens of groups A and B. Such findings are concordant with the investigation of Tronstad, Barnett and Cercone, ${ }^{21}$ who observed bacteria at the apical surface of 10 teeth with chronic lesions persisting after endodontic treatment. Tronstad, Kreshtool and Barnett ${ }^{22}$ confirmed the presence of biofilm, or dentobacterial plaque, firmly adhered to the apical root surface.

Bacteria were found in 38 samples out of the 48 periapical granulomas analyzed, either in isolation, organized in colonies, freestanding at the extracellular spaces or inside macrophage cells. The Brown-Brenn staining revealed predominance of Gram-positive and Gramnegative cocci and bacilli. Winkler, Mitchell and Healey ${ }^{23}$ found similar results in 15 extracted teeth with lesions adhered to their apexes, observing a uniform distribution of bacteria with mild to moderate concentrations, with prevalence of Gram-positive cocci and bacilli. Tronstad and Sunde $^{24}$ suggest that a periapical endodontic lesion is not as hostile to microorganisms as many have thought, indicating that an infection might not be limited to the root of the tooth, but include the periapical lesion as well. Differently than the present study, Langeland, Block and Grossman ${ }^{25}$ found microorganisms in just one out of 35 biopsies analyzed. The small amount of microorganisms observed in the apical region and periapical granulomas in some investigations may be due to technical limitations.

The highest difficulty found in the utilization of the Brown-Brenn staining lies in the observation of Gramnegative bacteria, which are often not or mildly stained. The cumulative effect of the chemicals employed for specimen processing leads the tissues to lose their staining affinity with the Brown-Brenn staining, ${ }^{26}$ and these limitations may yield erroneous or poorly sensitive outcomes.

It may be undoubtedly concluded that utilization of a method with higher sensitivity would add much value to this study, e.g. the method of in situ hybridization for identification of RNA in prokaryotic cells for bacterial identification, or methods of immunohistochemical staining. ${ }^{27}$ Despite these limitations, the results presented and discussed demonstrated to be compatible with those 
obtained by other authors ${ }^{10,21,22,26,28}$ employing the same method of tissue staining. Utilization of culture amplification methods, such as the PCR, would not bring further benefits, since it would not provide the location of the microorganisms present, which was one of the main objectives of this study. ${ }^{20}$

\section{CONCLUSION}

This study demonstrates the distribution of bacteria and bacterial biofilms in the entire root canal system of infected teeth with apical granulomas. In biofilm, different gradients of Chemicals, nutrients and oxygen create microenvironments to which microorganisms must adapt to survive. ${ }^{29}$ These findings suggest that bacterial infections are capable to reach inaccessible areas that cannot be removed by contemporary instruments and irrigation alone.

\section{REFERENCES}

1. Lappin-Scott HM, Costerton J. Microbial biofilms. New York: Cambridge University Press 1995.p.15-301.

2. Nair PNR. Light and electron microscopic studies of root canal flora and periapical lesions. J Endod 1987;13:29-39.

3. Kakehashi S, Stanley HR, Fitzgerald RJ. The effects of surgical exposure of dental pulps in germfree and conventional rats. Oral Surg Oral Med Oral Pathol 1965;20:340-349.

4. Tronstad L. Root resorption-etiology, terminology and clinical manifestations. Endod Dent Traumatol 1988;4:241-252.

5. Byström A, Sundqvist G. Bacteriologic evaluation of the efficacy of mechanical root canal instrumentation in endodontic therapy. Scand J Dent Res 1981;89:321-328.

6. Saunders WP, Saunders EM. Coronal leakage as a cause of failure in root canal therapy: a review. Endod Dent Traumatol 1994;10:105-108.

7. Wu MK, Wesselink PR. Endodontic leakage studies reconsidered. Part I. Methodology, application and relevance. Int Endod J 1993;26:37-43.

8. Oliet S. Single-visit endodontics: a clinical study. J Endod 1983;9:147-152.

9. Soltanoff W. A comparative study of the single-visit and the multiple-visit endodontic procedure. J Endod 1978;4:278-281.

10. Stabholz A, Walton RE. Evaluating success and failure. In: Walton RE, Torabinejad M, editors. Principles and practice of endodontics. 2nd ed. Philadelphia: WB Saunders; 1996; p.324-335.

11. Byström A, Happonen RP, Sjogren U, Sundqvist G. Healing of periapical lesions of pulpless teeth after endodontic treatment with controlled asepsis. Endod Dent Traumatol 1987;3:58-63.

12. Lin LM, Pascon EA, Skribner J, Gangler P, Langeland K. Clinical, radiographic and histologic study of endodontic treatment failures. Oral Surg Oral Med Oral Pathol 1991;71: 603-611.

13. Love RM. Regional variation in root dentinal tubule infection by Streptococcus gordonii. J Endod 1996;22:290-293.

14. Brown JH, Brenn L. A method for the differential staining of Gram-positive and Gram-negative bacteria in tissue sections. Bull Johns Hopkins Hosp 1931;48:69-73.
15. Ricucci D, Bergenholtz G. Bacterial status in root-filled teeth exposed to the oral environment by loss of restoration and fracture or caries: a histobacteriological study of treated cases. Int Endod J 2003;36:787-802.

16. Akapta ES, Blechman H. Bacterial invasion of pulpal dentin wall in vitro. J Dent Res 1982;61:435-438.

17. Neuvald LR, Consolaro A. Cemento enamel junction: microscopic analysis and external cervical resorption. J Endod 2000;26: 503-508.

18. Siqueira JF Jr, Uzeda M, Fonseca MEF. A scanning electron microscopic evaluation of in vitro dentinal tubules penetration by selected anaerobic bacteria. J Endod 1996;22:308-310.

19. Nair PNR, Henry S, Vera J. Microbial status of apical root canal system of human mandibular first molars with primary apical periodontitis after one-visit endodontic treatment. Oral Surg Oral Med Oral Pathol 2005;99:231-252.

20. Siqueira JF Jr, Rôças IN. Treponema socranskii in primary endodontic infections as detected by nested PCR. J Endod 2003;29:244-247.

21. Tronstad L, Barnett F, Cercone F. Periapical bacterial plaque in teeth refractory to endodontic treatment. Endod Dent Traumatol 1990;6:73-77.

22. Tronstad L, Kreshtool D, Barnett F. Microbiological monitoring and results of treatment of extraradicular endodontic infection. Endod Dent Traumatol 1990;6:129-136.

23. Birch RH, Melville TH, Neubert EW. A comparison of rootcanal and apical lesion flora. Brit Dent J 1964;116:350-352.

24. Tronstad L, Sunde PT. The evolving new understanding of endodontic infections. Endod Topics 2003;6:57-77.

25. Langeland K, Block RM, Grossman LI. A histopathologic and histobacteriologic study of 35 periapical endodontic surgical specimens. J Endod 1977;3:8-23.

26. Wijnbergen M, Van Mullem PJ. Effect of histological decalcifying agents on number and stainability of Gram-positive bacteria. J Dent Res 1987;66:1029-1031.

27. Matsuo T, Shirakami T, Ozaki K, Nakanishi T, Yumoto H, Ebisu S. An immunohistological study of the localization of bacteria invading root pulpal walls of teeth with periapical lesions. J Endod 2003;29:194-200.

28. Stabholz A, Sela MN. The role of oral microorganisms in the pathogenesis of periapical pathosis. I. Effect of Streptococcus mutans and its cellular constituents on the dental pulp and periapical tissue of cats. J Endod 1983;9:171-175.

29. Saini R, Saini S, Sharma S. Biofilm: A dental microbial infection. J Nat Sc Biol Med 2011;2:71-75.

\section{ABOUT THE AUTHORS}

\section{Francisco Carlos Ribeiro}

Professor, Department of Dental Clinics and Endodontics, Federal University of Espirito Santo, Espirito Santo, Brazil

\section{Alberto Consolaro}

Professor, Department of Oral Pathology, University of São Paulo São Paulo, Brazil

\section{Tiago Novaes Pinheiro (Corresponding Author)}

Professor, Department of Dentistry, Amazonas State University, Brazil e-mail: tiagonpinheiro@yahoo.com.br 